\title{
The effects of taste sensitivity and repeated taste exposure on children's intake and liking of turnip (Brassica rapa subsp. rapa); a bitter Brassica vegetable
}

Article

Accepted Version

Creative Commons: Attribution-Noncommercial-No Derivative Works 4.0

Mohd Nor, N. D., Houston-Price, C. ORCID:

https://orcid.org/0000-0001-6368-142X, Harvey, K. and Methven, L. (2021) The effects of taste sensitivity and repeated taste exposure on children's intake and liking of turnip (Brassica rapa subsp. rapa); a bitter Brassica vegetable. Appetite, 157. 104991. ISSN 0195-6663 doi: https://doi.org/10.1016/j.appet.2020.104991 Available at https://centaur.reading.ac.uk/93440/

It is advisable to refer to the publisher's version if you intend to cite from the work. See Guidance on citing.

To link to this article DOI: http://dx.doi.org/10.1016/j.appet.2020.104991

Publisher: Elsevier

All outputs in CentAUR are protected by Intellectual Property Rights law, including copyright law. Copyright and IPR is retained by the creators or other copyright holders. Terms and conditions for use of this material are defined in the End User Agreement. 


\section{www.reading.ac.uk/centaur}

\section{CentAUR}

Central Archive at the University of Reading

Reading's research outputs online 
The effects of taste sensitivity and repeated taste exposure on children's intake and liking of turnip (Brassica rapa subsp. rapa); a bitter Brassica vegetable

Nurfarhana Diana Mohd Nor ${ }^{1,3}$, Carmel Houston-Price ${ }^{2}$, Kate Harvey $^{2}$, Lisa Methven ${ }^{3 *}$

${ }^{1}$ Department of Early Childhood Education, Faculty of Human Development, Sultan Idris Education University, 35900 Tanjong Malim, Perak, Malaysia

${ }^{2}$ School of Psychology and Clinical Language Sciences, University of Reading, Early Gate, Whiteknights, Reading, RG6 6AL, UK

$10{ }^{3}$ Sensory Science Centre, Department of Food and Nutritional Sciences, University of Reading,

11 Whiteknights, Reading, RG6 6AP, UK

12

*Corresponding author: Professor Lisa Methven

E-mail: 1.methven@ reading.ac.uk

15

Present address: Department of Food and Nutritional Sciences, The University of Reading, PO Box 226, Whiteknights, Reading, RG6 6AP, UK

Phone number: +44(0) 1183788714 


\begin{abstract}
Low consumption of vegetables in children is a concern around the world, hence approaches aimed at increasing intake are highly relevant. Previous studies have shown that repeated taste exposure is an effective strategy to increase vegetable acceptance. However, few studies have examined the effect of repeated taste exposure on children varying in bitter taste sensitivity. This study investigated the influence of taste genotypes and phenotypes on the effects of repeated taste exposure to a Brassica vegetable. 172 preschool children aged 3 to 5 years were recruited into this study. Turnip was selected as the target vegetable and parents completed a questionnaire to ensure unfamiliarity. During the intervention, children were exposed to steamed-pureed turnip for 10 days (once/day). Intake and liking were measured before, during and after the intervention, and a follow-up was done 3 months post-intervention. Taste genotypes (TAS2R38 and gustin (CAO) genotypes) and taste phenotypes (PROP taster status and fungiform papillae density) were determined. There was a significant effect of exposure shown by significant increases in intake $(\mathrm{p}<0.001)$ and liking $(\mathrm{p}=0.008)$ post-intervention; however, there were no significant effects of taste genotypes or phenotypes on intake and liking. In summary, repeated taste exposure is confirmed to be a good strategy to increase vegetable acceptance in children, regardless of bitter taste sensitivity.
\end{abstract}

Keywords: repeated taste exposure, bitter taste sensitivity, Brassica, turnip, children, TAS2R38, gustin 


\section{Introduction}

Adequate consumption of vegetables has been shown to be associated with positive health outcomes and may provide protection against chronic diseases such as heart disease, stroke, diabetes and cancers (Dias, 2012). Phytochemicals such as carotenoids, flavonoids, glucosinolates, vitamins and minerals are potential anticarcinogenic compounds found in vegetables (Van Duyn \& Pivonka, 2000). Despite these health benefits, vegetable intake in both children and adults is reported to be below recommendation in the UK (Bates et al., 2014; Bates et al., 2016) as well as in other countries globally (Micha et al., 2015). One serious concern for children being that eating habits in childhood are a determinant of adult diet (Mikkilä, Räsänen, Raitakari, Pietinen, \& Viikari, 2004).

Many researchers have suggested that low consumption or avoidance of certain foods is due to food neophobia, a condition defined as a reluctance to try unfamiliar foods (Pelchat \& Pliner, 1995). Cooke, Wardle, \& Gibson (2003) found that greater food neophobia in 2- to 6-year-old children was related to lower consumption of vegetables, fruits and meat. They suggested that these foods (especially vegetables) are avoided because they may contain toxins; food neophobia serves to protect humans from ingesting these potentially dangerous foods. Similar results were found in a study by Russell \& Worsley (2008), which revealed that food neophobia in 2- to 5-year-old children has the strongest impact on intake of vegetables followed by meat and fruits. These studies suggest that food neophobia is crucial in determining children's dietary intake and food preferences.

Innate preferences pose another challenge to promoting vegetable consumption. Humans are born with an innate preference for sweet tastes and a tendency to reject bitter tastes (Galindo, Schneider, Stähler, Töle, \& Meyerhof, 2012), which leads to children eating sweet foods but avoiding vegetables, particularly the bitter ones (Wardle, Sanderson, Gibson, \& Rapoport, 2001). Furthermore, taste sensitivity could also be a barrier, as studies show that individuals who are more sensitive to bitter taste consume fewer vegetables than less sensitive individuals (Duffy et al., 2010; Sacerdote et al., 2007; Sandell et al., 2014), although this effect has not been confirmed in all studies (Feeney, O’Brien, Scannell, Markey, \& Gibney, 2014).

Studies of bitter taste sensitivity often use 6-n-propylthiouracil (PROP) or phenylthiocarbamide (PTC), bitter compounds that have a thiourea group. Although PROP and PTC are synthetic compounds, the thiourea moiety is found within glucosinolate compounds present in Brassica vegetables (Keller \& Adise, 2016). The ability to taste PROP/PTC is genetically determined (Barajas-Ramírez, Quintana-Castro, Oliart-Ros, \& Angulo-Guerrero, 2016) where the $T A S 2 R 38$ gene which encodes a bitter taste receptor is predominantly responsible for the taste detection of the thiourea group (Bufe et al., 2005). There are 3 common single nucleotide polymorphisms (SNPs) (rs713598, rs 1726866 and $r s 10246939)$ that can be found within TAS2R38 genotype which give rise to 3 common haplotypes (PAV/PAV, PAV/AVI and AVI/AVI) (Kim, Wooding, Ricci, Jorde, \& Drayna, 2005). Kim et al. (2003) discovered that individuals with PAV/PAV genotype are PTC super-tasters, while those who carry PAV/AVI and AVI/AVI are medium-tasters and non-tasters, respectively. Previous studies have concluded that PAV/PAV individuals perceive greater bitterness from Brassica vegetables than AVI/AVI individuals, and that this can influence their liking (Sandell \& Breslin, 2006; Shen, Kennedy, \& Methven, 2016). In contrast, Duffy et al., (2010) reported that the AVI/AVI individuals had a lower consumption of vegetables (regardless of vegetable type) compared to the other two common genotypes. 
In addition to this specific bitter genotype, sensitivity to all tastes is often associated with fungiform papillae density (FPD) (Hayes, Sullivan, \& Duffy, 2010; Yackinous \& Guinard, 2002). Duffy et al. (2010) found that individuals with high FPD perceived PROP as more bitter than low FPD individuals, which might then influence the high FPD individuals to consume fewer bitter vegetables. However the association between these two factors remain inconclusive as there are studies which report that PROP responsiveness was not related to FPD (Dinnella et al., 2018; Fischer et al., 2013; Garneau et al., 2014; Piochi et al., 2019).

In relation to FPD, Henkin, Martin and Agarwal (1999) suggested that gustin (CA6) genotype plays an important role in taste bud development and Padiglia et al. (2010) reported that individuals who are PROP tasters carry A/A genotype more frequently, while non-tasters tend to carry G/G genotype on CA6 SNP rs2274333.

Many strategies have been tested with the intention of encouraging children to eat more vegetables; one of them is repeated taste exposure. Repeated tastings contribute to food familiarity, which is an important determinant of food liking in children (Birch, 1999). Therefore, exposure to vegetables can be effective in increasing vegetable intake and liking in children. Repeated taste exposure has been proposed to be effective for various age ranges; from infants and preschoolers to schoolchildren (Wardle et al., 2003a). Anzman-Frasca, Savage, Marini, Fisher and Birch (2012) and Wardle, Herrera, Cooke and Gibson (2003b) found that 8 exposures of novel and disliked vegetables increased the vegetable acceptance in children aged 3 to 7 years while Lakkakula, Geaghan, Zanovec, Pierce and Tuuri (2010) found that 10 exposures increased acceptance of disliked vegetables in primary school children. Other studies also reported that 10 exposures are effective to increase intake of a vegetable in preschool children (Caton et al., 2013) and infants (Remy, Issanchou, Chabanet, \& Nicklaus, 2013). Furthermore, a review by Spill et al. (2019) reported that 8-10 or more exposures can increase fruit and vegetable acceptability in children ages 4 to 24 months. Appleton, Hemingway, Rajska, \& Hartwell (2018) reported that multiple exposures to a vegetable can also increase intake of other vegetables.

However, to date, no study has measured the effectiveness of repeated taste exposure in relation to both taste genotype and phenotype. Thus, the present study aimed to determine the effects of repeated taste exposure on acceptance of an unfamiliar Brassica vegetable among children with varying bitter taste sensitivity. Four different methods were used to assess taste sensitivity, two exploring the genotypes known to relate to bitter taste sensitivity and two to explore the behavioural phenotype. We hypothesised that repeated taste exposure would increase vegetable acceptance in all children, with children who are less sensitive to bitter taste showing a greater increase than children who are more sensitive to bitter taste.

\section{Materials and methods}

Study design: The study was given a favourable opinion for conduct by the University of Reading Research Ethics Committee (study number 14/40). Following a pre-intervention test of intake, children received 10 exposures (once/attended school day) of steamed-pureed turnip, after which it was offered once again at a post-intervention test. The primary outcome measure was intake of steamed-pureed turnip and rated liking was the secondary outcome. A follow-up was done 3 months after post-intervention to assess the durability of the effects of repeated taste exposure. 
Recruitment: A letter explaining the purpose and protocol of the study was sent to primary schools in Reading and Wokingham (Berkshire, UK). Once permission was granted from the head teacher, parents were given an information sheet explaining the details of the study as well as a consent form for them to sign if they agreed to their child participating.

Power calculation: Data from a previous study was used to estimate the minimum number of children required in this study, assuming a mean difference in intake of $4.9 \mathrm{~g}$ after an exposure period, with a standard deviation of $8.16 \mathrm{~g}$ (Wardle et al., 2003a), a significance level of $\mathrm{p}=0.05$ (one sided) and a power of $80 \%$. Enough children were needed in each TAS2R38 PAV/PAV, PAV/AVI and AVI/AVI group to allow comparisons between genotypes. This power calculation indicated that 44 children (Fig. 1) were needed for each genotype group. Taking into account an expected dropout rate of $10 \%$, the target number of children was 48 per group. The proportion of the population with the 3 common TAS2R38 genotype groups is approximately $25 \%$ of PAV/PAV, $50 \%$ of PAV/AVI and 25\% of AVI/AVI (Duffy et al., 2004), so to ensure the required number of 48 in each group, the aim was to recruit 200 children.

$$
\begin{aligned}
& \mathrm{n}>2 \mathrm{~F}(\sigma / \mathrm{d})^{2} \\
& \mathrm{n}>2(7.85) \times(8.16 / 4.9)^{2} \\
& \mathrm{n}>15.7 \times 2.77 \\
& \mathrm{n}>44
\end{aligned}
$$

216 Fig. 1: Power calculation to determine number of participants in this study.

Participants: 172 children ( 82 males and 90 females) aged between 3 years 1 month to 5 years 7 months (mean age: 4 years 9 months) were recruited from 6 schools. The inclusion criterion was that children needed to be unfamiliar with turnip, as reported by their parents. The exclusion criteria were allergy to turnip, prior familiarity with turnip, as reported by parents, and liking of the steamed-pureed turnip given at pre-intervention test. No child met the exclusion criteria.

Selection of target vegetable: Turnip (Brassica rapa subsp. rapa) was selected as the target vegetable as it is one of the most unfamiliar Brassica vegetables in the UK, based on a previous study that used a 'Food Familiarity and Liking Questionnaire' which included fruits and vegetables (Heath, 2012). Samples were prepared either in the primary school's kitchen or the sensory kitchen at the Department of Food and Nutritional Sciences, University of Reading, UK, by identical means. The tuber part was used in the preparation of the samples. Prior to cooking, turnips were peeled and stems and tails removed, then washed and sliced to a thickness of approximately $0.5 \mathrm{~cm}$. Approximately $2.4 \mathrm{~kg}$ of sliced turnips were placed into an electric 3-tier steamer (Tefal) ( $800 \mathrm{~g}$ in each tier), with $1 \mathrm{~L}$ of water added to the base of the steamer, and steamed initially for $25 \mathrm{~min}$. Subsequently, sliced turnips from tier 1 were transferred to tier 3 and vice versa (to ensure equal heat circulation), water was added again up to $1 \mathrm{~L}$ and the turnips were steamed for another $25 \mathrm{~min}$. Turnips were then blended using a hand blender (Russell Hobbs) for approximately 5 min until the texture was smooth. All cooked turnips were then placed into plastic containers, labelled and stored in a freezer at $-18^{\circ} \mathrm{C}$ prior to testing. The sensory profile of the steamed-pureed turnip was described and rated by a trained sensory panel as summarised in Supplementary A (Table S2). This confirmed that the final 
product, as served to children in this study, had a characteristic bitter taste in addition to sweet

Vegetable serving: Prior to serving, the steamed-pureed turnip was defrosted, reheated in a microwave $(800 \mathrm{~W})$ and stirred every $2 \mathrm{~min}$ until the temperature reached $>75^{\circ} \mathrm{C}$. At pre- and post-intervention tests, on Day 5 and 8 of exposure and at follow-up, $100 \mathrm{~g}$ of steamed-pureed turnip was served in a $230 \mathrm{ml}$ transparent plastic serving dish and labelled with each participant's code; a plastic teaspoon was provided. On Day 1, 2, 3, 4, 6, 7, 9 and 10 of exposure, approximately $5 \mathrm{~g}$ of steamed-pureed turnip was given to the children on a plastic teaspoon. The puree was served warm (approximately 40 to $45^{\circ} \mathrm{C}$ ) in rooms varying in temperature between approximately $20^{\circ} \mathrm{C}$ and $24^{\circ} \mathrm{C}$.

Repeated taste exposure test: Before the study began, researchers attended 2 sessions (minimum 2 hours per session) at each school, so that they were familiar to the children. Parents completed a 'Vegetable preference and familiarity' questionnaire that comprised a list of 46 Brassica and non-Brassica vegetables to determine children's familiarity with and liking of turnip.

At pre- and post-intervention tests, Day 5, Day 8 of the exposure period and follow-up, children were given one pot of $100 \mathrm{~g}$ of steamed-pureed turnip. Children were individually taken out of their classes to a separate room. They were asked to eat as much as or as little as they wanted. No persuasion or force was used. Intake and liking of the puree were measured at these times. For the rest of the exposure days (Day 1, 2, 3, 4, 6, 7, 9 and 10), only 1 teaspoon (approximately $5 \mathrm{~g}$ ) of the puree was given, intake and liking were not measured, but refusal to eat was monitored. At these times, children were taken out of their classes in groups of between 2 and 5 children.

Intake was measured in grams (g) using a digital weighing scale (3 decimal places) (Salter). Liking was assessed using a 3-point hedonic scale. Using hedonic scales with this age group is challenging (Chen, Resurreccion, \& Paguio, 1996), and researchers took several steps to increase the reliability of the data. Cartoon faces were used (one with a deep frown, one a neutral face and one with a broad smile) alongside child-friendly descriptors ('yucky', 'just okay' and 'yummy'). These were coded as 1, 2 and 3 respectively for analysis. In addition, children were asked to describe the taste when they completed the scoring. This provided researchers with the opportunity to check that children had understood the scale, for example when a child's facial expression did not appear to align to their score. When this happened, researchers explained the scoring again to ensure the child understood.

DNA extraction and genotyping: Buccal swab samples were collected at schools after the end of the intervention. The DNA samples were collected by rubbing a Isohelix DNA buccal swab on the inside of a child's cheeks and then stored until DNA extraction at room temperature and kept dry through the use of Isohelix Dri-Capsules (Cell Projects Ltd, Kent, UK). The researcher swabbed both cheeks of each child for approximately $1 \mathrm{~min}$ on each cheek. The swabs were sent to IDna Genetics Ltd. (Norwich, UK) for extraction and genotyping, with $10 \%$ of the swabs sent as blinded replicates to ensure accuracy. DNA were extracted using Isohelix Buccalyse DNA Extraction Kit (Cell Projects, Kent, UK) according to the manufacturer's instructions, then diluted 1:8 with water prior to analysis. Polymorphisms of TAS $2 R 38$ ( $r s 713598, r s 1726866$ and $r s 10246939)$ and $C A 6$ ( $r s 2274333)$ were analysed using the KASP genotyping chemistry (LGC Group, Middlesex, UK). Diluted DNA was dried into 384-well PCR plates (Life Technologies, UK) then $5 \mu \mathrm{L}$ of KASP Master mix (LGC Group, Middlesex, 
UK) and primers were added. PCR amplification was performed as follows: $94^{\circ} \mathrm{C}$ for $15 \mathrm{~min}$, $94^{\circ} \mathrm{C}$ for $15 \mathrm{~s}, 65^{\circ} \mathrm{C}$ for $20 \mathrm{~s}, 94^{\circ} \mathrm{C}$ for $15 \mathrm{~s}, 57^{\circ} \mathrm{C}$ for $20 \mathrm{~s}$ (Life Technologies, UK). The fluorescent products were detected in an Applied Biosystems instrument (Life Technologies, $\mathrm{UK})$.

PROP taster status: PROP taster status was determined by using filter papers impregnated with PROP and these were prepared as described in Zhao, Kirkmeyer and Tepper (2003). Approximately $10 \mathrm{~g}$ of PROP (HPLC grade) (Sigma-Aldrich) was dissolved in $1000 \mathrm{~mL}$ boiled spring water (Harrogate Spring water, UK) on a stirring hotplate to prepare a $50 \mathrm{mmol} / \mathrm{L}$ PROP solution. Filter paper disks (Whatman Grade 1, $30 \mathrm{~mm}$ in diameter, Sigma-Aldrich Cat No: 1001-030) were then placed into the PROP solution for $30 \mathrm{~s}$ then taken out. The filter paper disks were then placed on a tray wrapped with aluminium foil and then dried in an oven for 1 h at $121^{\circ} \mathrm{C}$.

At the end of all study visits, children were asked to take a sip of water and then the PROP impregnated filter paper was placed on the tip of their tongue for a few seconds until the paper was wet, and removed. A simple forced-choice method was used, adapted from Keller, Steinmann, Nurse and Tepper's (2002) method, which has a high test-retest reliability ( $\mathrm{r}=0.92)$. Children were asked a question 'Did you taste anything?' Those who answered 'no', were categorised as non-tasters. Those who reported the filter paper has a taste were then questioned as to what it tasted like. Responses of 'bad', 'bitter' and 'yucky' were recorded as tasters. Those who did not verbally state the filter paper had a taste but who exhibited rejection signs such as grimacing or frowning were also categorised as tasters.

Fungiform papillae counts: The method to count FPD was adapted from Feeney and Hayes (2014). The tongue was dried and coloured using a blue food colouring (Sainsbury's, UK). A $1 \mathrm{~cm}^{2}$ paper was cut and paste on a ruler as a marker, then the ruler was placed next to the tongue. Photographic images (tongue including the square on the ruler) were taken using a digital camera (Canon EOS 700D) on macro setting. Approximately 3 to 10 images were taken for each child and the best image was used to count the papillae; the fungiform papillae identify as pink circles against a blue background. Images were viewed in Microsoft Office Power Point 2013 where the outer square on the ruler was drawn to enable the square to be moved to middle, left and right areas of the tip of the tongue. The left and right areas have been shown to be reliable measures of FPD (Shahbake, Hutchinson, Laing, \& Jinks, 2005). There was a high correlation between mean FPD of left and right area and mean FPD of middle area of the tongue $(\mathrm{r}=0.94, \mathrm{p}<0.001)$, hence the middle area was used in this analysis in order to include data from the first 2 schools where only a single "middle" count had been taken. All fungiform papillae in a $1 \mathrm{~cm}^{2}$ stained area were counted by 2 researchers to ensure accuracy $(\mathrm{r}=0.94, \mathrm{p}<0.001)$. Quartile calculation was used to categorise children into 3 groups (low, medium and high FPD); the upper quartile as the high FPD, the lower quartile as the low FPD and the middle two quartiles as the medium FPD group.

Statistical analysis: Shapiro-Wilk tests showed that the data were not normally distributed. Both parametric and non-parametric tests were used to analyse data, and both sets of analyses revealed the same main effects. Therefore, only parametric tests are reported as these allowed testing of the interactions between main effects. Paired t-tests were used to compare means of intake and liking between 2 time points. One-way repeated measure ANOVAs were used to compare mean intake and liking across 3 or 4 time points. To evaluate the effects of taste sensitivity and time on intake and liking, we used mixed ANOVAs with time as a withinsubjects factor and taste sensitivity group (taste genotype group or taste phenotype group) as a 
between-subjects factor. Bonferroni tests were used for post hoc with a significance value of $\mathrm{p}<0.05$. Associations between groups of categorical data were analysed using Chi-square tests. All analyses were performed using SPSS (version 21, New York, USA).

\section{Results}

Of the 172 children who participated in this study, only 134 children had complete data sets which included data for intake and liking (at pre- and post-intervention), and all taste sensitivity measurements (TAS2R38, CA6, PROP taster status and FPD). These data were then used for the main analyses. Data analyses by excluding missing data according to individual taste sensitivity measurement were also performed to maximise number of children. However results were consistent with the analyses using complete data sets. Hence, only results of complete data sets are reported. Taste genotype and phenotype characteristics of children are described in Table 1.

Table 1: Taste genotype and phenotype characteristics of participants with complete data $(n=134)$.

\begin{tabular}{lll}
\hline Characteristic & & n (\%) \\
\hline TAS2R38 & PAV/PAV & $22(16.4)$ \\
& PAV/AVI & $67(50.0)$ \\
& AVI/AVI & $33(24.6)$ \\
& PAV/AAI & $3(2.2)$ \\
& PAV/AAV & $2(1.5)$ \\
& AAI/AAI & $1(0.7)$ \\
& AAV/AAI & $1(0.7)$ \\
& AAV/AVI & $1(0.7)$ \\
CA6 & AAI/AVI & $4(3.0)$ \\
& A/A & $62(46.3)$ \\
PROP taster status & A/G & $56(41.8)$ \\
& G/G & $16(11.9)$ \\
FPD & Taster & $108(80.6)$ \\
& Non-taster & $26(19.4)$ \\
& High $\left(57\right.$ to 113 papillae/cm $\left.{ }^{2}\right)$ & $33(24.6)$ \\
& Medium $\left(36\right.$ to 56 papillae/cm $\left.{ }^{2}\right)$ & $63(47.0)$ \\
& Low (17 to 35 papillae/cm $\left.{ }^{2}\right)$ & $38(28.4)$ \\
\hline
\end{tabular}

358
$16.4 \%$ of children had PAV/PAV TAS2R38 genotype, 50.0\% were PAV/AVI, $24.6 \%$ were AVI/AVI and $8.8 \%$ had a rare genotype (PAV/AAV, PAV/AAI, AAI/AVI, AAV/AAI, AAI/AAI and AAV/AVI). $46.3 \%$ carried A/A CA6 genotype, $41.8 \%$ carried A/G genotype and $11.9 \%$ had G/G genotype. For taste phenotype, the majority of participants $(80.6 \%)$ were categorised as PROP tasters while $19.4 \%$ were non-tasters, similar to the proportions reported in previous studies (Bouthoorn et al., 2014; Lumeng, Cardinal, Sitto, \& Kannan, 2008). In addition, quartile calculation showed that $24.6 \%$ had high FPD, $47.0 \%$ had medium FPD and $28.4 \%$ had low FPD. Ethnicity was known only for 91 children; based on the Office for National Statistics's (2015) ethnicity classification in England, 40 children were white, 27 children were Asian/Asian British, 11 children were Black/African/Caribbean/Black British, 10 children were mixed/multiple ethnic and 3 children were in 'other' ethnic group. 
Relationship between taste genotypes and phenotypes: Distribution of TAS2R38, CA6 genes and FPD according to PROP taster status are shown in Table 2. The majority of the children who carried PAV/PAV TAS2R38 $(\mathrm{n}=20 / 22)$, A/A CA6 genotypes $(\mathrm{n}=52 / 62)$ or had high FPD $(n=26 / 33)$ were PROP tasters. In contrast, 2 PAV/PAV children were non-tasters and 27 AVI/AVI children were tasters, 10 non-tasters had A/A and 9 tasters had G/G CA6 genotypes. Additionally, 7 children with high FPD were categorised as non-tasters and 33 children with low FPD were tasters.

Table 2: Relationship between taste genotypes and phenotypes (full data set, $n=134$ ).

\begin{tabular}{llll}
\hline \multirow{2}{*}{ Genotypes and phenotypes } & \multicolumn{2}{c}{ PROP taster status } \\
\cline { 3 - 4 } TAS2R38 & Taster & Non-taster \\
& PAV/PAV & 20 & 2 \\
& PAV/AVI & 53 & 14 \\
& AVI/AVI & 27 & 6 \\
& PAV/AAI & 3 & 0 \\
& PAV/AAV & 2 & 0 \\
& AAI/AAI & 1 & 0 \\
& AAV/AAI & 0 & 1 \\
& AAV/AVI & 0 & 1 \\
& AAI/AVI & 2 & 2 \\
& A/A & 52 & 10 \\
& A/G & 47 & 9 \\
FPD & G/G & 9 & 7 \\
& High (57 to 113 papillae $\left./ \mathrm{cm}^{2}\right)$ & 26 & 7 \\
& Medium (36 to 56 papillae $\left./ \mathrm{cm}^{2}\right)$ & 49 & 14 \\
& Low (17 to 35 papillae $\left./ \mathrm{cm}^{2}\right)$ & 33 & 5 \\
\hline
\end{tabular}

380

381

382

383

384

Chi-square tests were used to determine associations between genotypes and phenotypes. To avoid counts below 5, 2 genotype groups within TAS $2 R 38$ and $C A 6$ were combined. The PAV/PAV TAS2R38 genotype was combined with the PAV/AVI genotype into one group as both groups have the sensitive PAV haplotype. The PAV/PAV-PAV/AVI group would be expected to have more tasters than the AVI/AVI group. For $C A 6$, the A/G and G/G genotype were combined as both groups have the recessive allele $\mathrm{G}$, where it would be expected that children in the A/G-G/G group have less FPD compared to the A/A group (dominant allele). Results showed that there were no significant associations between TAS2R 38 and PROP taster status $\left(\chi^{2}(1)=0.001, \mathrm{p}=0.98\right)$, between FPD and PROP taster status $\left(\chi^{2}(2)=1.34, \mathrm{p}=0.51\right)$ or between $C A 6$ genotype and PROP taster status $\left(\chi^{2}(1)=0.79, \mathrm{p}=0.37\right)$. There were no other associations found: $C A 6$ and FPD $\left(\chi^{2}(2)=1.18, \mathrm{p}=0.55\right), T A S 2 R 38$ and $C A 6\left(\chi^{2}(1)=0.59\right.$, $\mathrm{p}=0.44), T A S 2 R 38$ and FPD $\left(\chi^{2}(2)=0.63, \mathrm{p}=0.73\right)$. These results showed that taste genotypes and phenotypes were independent of one another in this study.

Effects of repeated taste exposure on intake and liking of steamed-pureed turnip: Results revealed that overall intake significantly increased post-intervention from $14.8 \pm 24.0 \mathrm{~g}$ to 29.8 $\pm 34.9 \mathrm{~g}(\mathrm{t}(133)=-6.17, \mathrm{p}<0.001)$ (Fig. 2). Overall liking increased significantly from $2.3 \pm 0.9$ to $2.5 \pm 0.8$ post-intervention $(\mathrm{t}(133)=-2.35, \mathrm{p}=0.02)$ (Fig. 3$)$. 


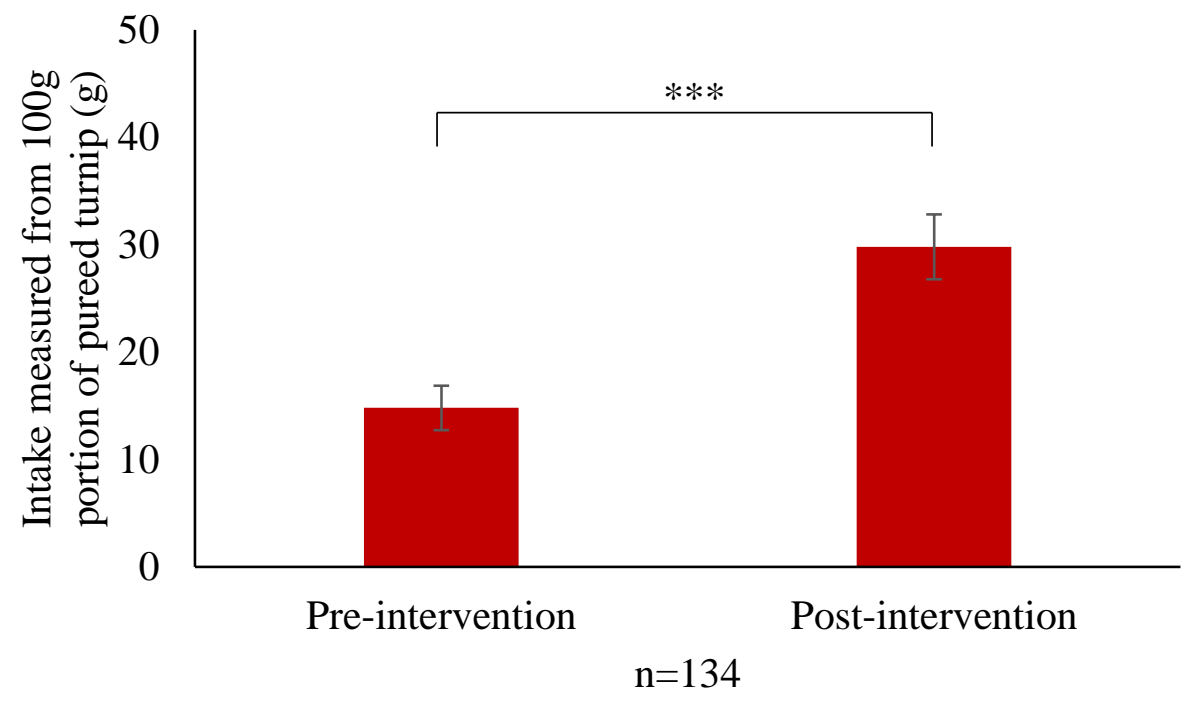

Fig. 2: Overall intake for steamed-pureed turnip at pre- and post-intervention. Values are means \pm SEM. $* * * \mathrm{p}<0.001$.

403

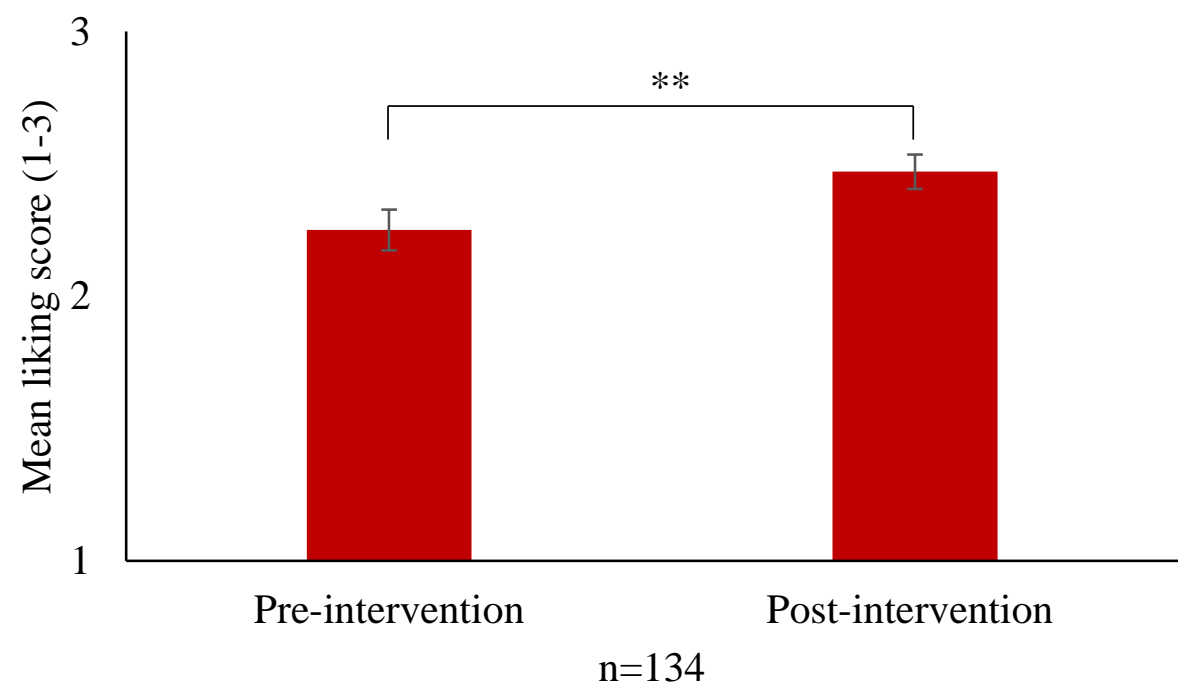

Fig. 3: Overall liking scores for steamed-pureed turnip at pre- and post-intervention. Values are means \pm SEM. $* * p<0.01$.

404 Vegetable intake pre and post repeated exposure according to taste genotypes and 405 phenotypes:

TAS2R38: To investigate the effect of TAS2R38 genotype on the change in intake with time 408 (pre- or post-intervention), a mixed model ANOVA (2 (time) x 3 (genotype)) was conducted. 409 Results confirmed the significant main effect of time (exposure) on intake $(F(1,119)=31.19$, $\left.410 \mathrm{p}<0.001, \eta_{p}^{2}=0.21\right)$ with intake increasing significantly post-intervention; however there was 411 no significant main effect of $\operatorname{TAS} 2 R 38\left(\mathrm{~F}(2,119)=0.08, \mathrm{p}=0.93, \eta_{p}^{2}=0.001\right)$ and no interaction 
412 between time and $\operatorname{TAS} 2 R 38\left(\mathrm{~F}(2,119)=0.68, \mathrm{p}=0.51, \eta_{p}^{2}=0.01\right)(\mathrm{Fig} .4)$. Similarly, the analysis 413 confirmed the main effect of time on liking $\left(\mathrm{F}(1,119)=6.12, \mathrm{p}=0.02, \eta_{p}^{2}=0.05\right)$ but no 414 significant main effect of TAS2R38 was found $\left(\mathrm{F}(2,119)=1.75, \mathrm{p}=0.18, \eta_{p}^{2}=0.03\right)$ and no 415 interaction between time and $\operatorname{TAS} 2 \operatorname{R} 38\left(\mathrm{~F}(2,119)=0.37, \mathrm{p}=0.69, \eta_{p}^{2}=0.01\right)$.

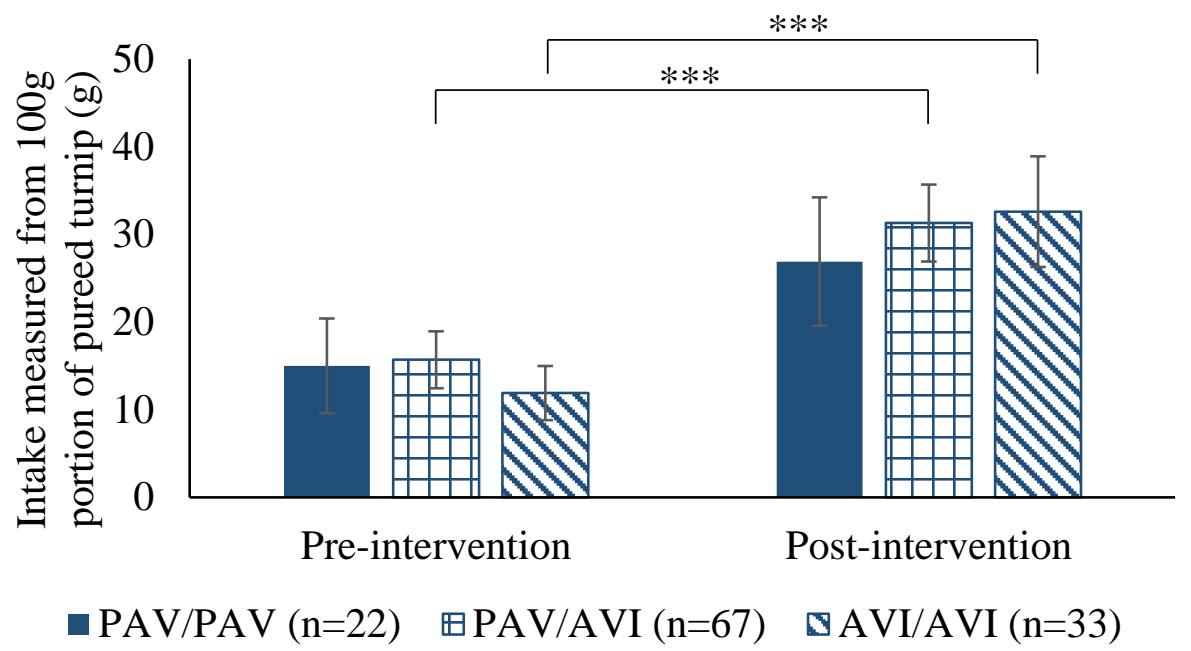

Fig. 4: Intake for steamed-pureed turnip at pre- and post-intervention for participants within each TAS $2 R 38$ genotype group. Values are means \pm SEM. $* * * p<0.001$.

416

417

418

419

420

421

422

423

424

425

426

427

428

429

430

431

432

433

434

Gustin (CA6): Results from a mixed model ANOVA (2 (time) x 3 (genotype)) confirmed that there was a significant main effect of time on intake $\left(\mathrm{F}(1,131)=32.55, \mathrm{p}<0.001, \eta_{p}^{2}=0.20\right)$ but there was no significant main effect of $C A 6\left(\mathrm{~F}(2,131)=0.11, \mathrm{p}=0.90, \eta_{p}^{2}=0.002\right)$ and no interaction between time and $C A 6\left(\mathrm{~F}(2,131)=0.89, \mathrm{p}=0.42, \eta_{p}^{2}=0.01\right)$ (supplementary Fig. $\left.\mathrm{S} 1\right)$. In the analysis of the effect of the $C A 6$ genotype and exposure (time) on liking, the main effect of time was not significant $\left(\mathrm{F}(1,131)=3.65, \mathrm{p}=0.06, \eta_{p}^{2}=0.03\right)$. There was no significant effect of $C A 6\left(\mathrm{~F}(2,131)=0.32, \mathrm{p}=0.73, \eta_{p}^{2}=0.01\right)$ and no interaction $\left(\mathrm{F}(2,131)=0.54, \mathrm{p}=0.58, \eta_{p}^{2}\right.$ $=0.01)$.

PROP taster status: Analysis of a mixed model ANOVA (2 (time) x 2 (PROP taster status)) again confirmed the main effect of time on both intake $\left(F(1,132)=29.19, \mathrm{p}<0.001, \eta_{p}^{2}=0.18\right)$ and liking $\left(\mathrm{F}(1,132)=4.49, \mathrm{p}=0.04, \eta_{p}^{2}=0.03\right)$ but with no significant main effect of PROP taster status $\left(\mathrm{F}(1,132)=1.47, \mathrm{p}=0.23, \eta_{p}^{2}=0.01 ; \mathrm{F}(1,132)=0.92, \mathrm{p}=0.34, \eta_{p}^{2}=0.01\right.$, respectively $)$ and no significant interaction between time and PROP taster status $\left(\mathrm{F}(1,132)=0.75, \mathrm{p}=0.39, \eta_{p}^{2}\right.$ $=0.01 ; \mathrm{F}(1,132)=0.19, \mathrm{p}=0.67, \eta_{p}^{2}=0.001$, respectively) (supplementary Fig. S2).

Fungiform papillae density (FPD): Analysis of a mixed model ANOVA (2 (time) x 3 (FPD group)) again confirmed the significant main effect of time on intake $(F(1,131)=35.51$, 
$\left.\mathrm{p}<0.001, \eta_{p}^{2}=0.21\right)$ but there was no significant main effect of FPD $(\mathrm{F}(2,131)=1.18, \mathrm{p}=0.31$, $\left.\eta_{p}^{2}=0.02\right)$ and no interaction $\left(\mathrm{F}(2,131)=2.40, \mathrm{p}=0.10, \eta_{p}^{2}=0.04\right)$ (supplementary Fig. S3). For

437 liking, the significant main effect of time was confirmed $\left(\mathrm{F}(1,131)=4.84, \mathrm{p}=0.03, \eta_{p}^{2}=0.04\right)$ but there was no significant main effect of $\operatorname{FPD}\left(\mathrm{F}(2,131)=0.54, \mathrm{p}=0.59, \eta_{p}^{2}=0.01\right)$ and no interaction $\left(\mathrm{F}(2,131)=0.03, \mathrm{p}=0.97, \eta_{p}^{2}<0.001\right)$. Overall liking significantly increased postintervention.

441

These analyses demonstrate that there were significant increases in intake and liking of steamed-pureed turnip from pre- to post-intervention, irrespective of taste genotypes and phenotypes.

Vegetable acceptance during the exposure days: In these analyses, data at Day 5 and 8 of exposure were included to compare mean intake and liking at 4 different time points. Out of 134 children used for previous analyses, only 132 children had intake and liking data at all 4 448 time points (pre-intervention, Day 5, Day 8 and post-intervention). 4-point one way repeated measures ANOVA again confirm the significant main effect of time on intake $(\mathrm{F}(2.4$, $\left.319.3)=20.37, \mathrm{p}<0.001, \eta_{p}^{2}=0.14\right)$. Intake significantly increased from pre-intervention $(15.0 \pm$ $24.1 \mathrm{~g})$ to Day $5(21.6 \pm 28.9 \mathrm{~g}, \mathrm{p}=0.002)$, remained constant at Day $8(22.7 \pm 30.6 \mathrm{~g}, \mathrm{p}=1.00)$ and increased again at post-intervention $(30.3 \pm 35.0 \mathrm{~g}, \mathrm{p}<0.001)$ (Fig. 5).

For liking, the significant main effect of time was again confirmed $(\mathrm{F}(2.5,320.6)=5.25$, 456 $\left.\mathrm{p}=0.003, \eta_{p}^{2}=0.04\right)$ where liking significantly increased from pre-intervention $(2.3 \pm 0.9)$ to 457 Day $5(2.6 \pm 0.7, \mathrm{p}=0.004)$ and remained stable until post-intervention.

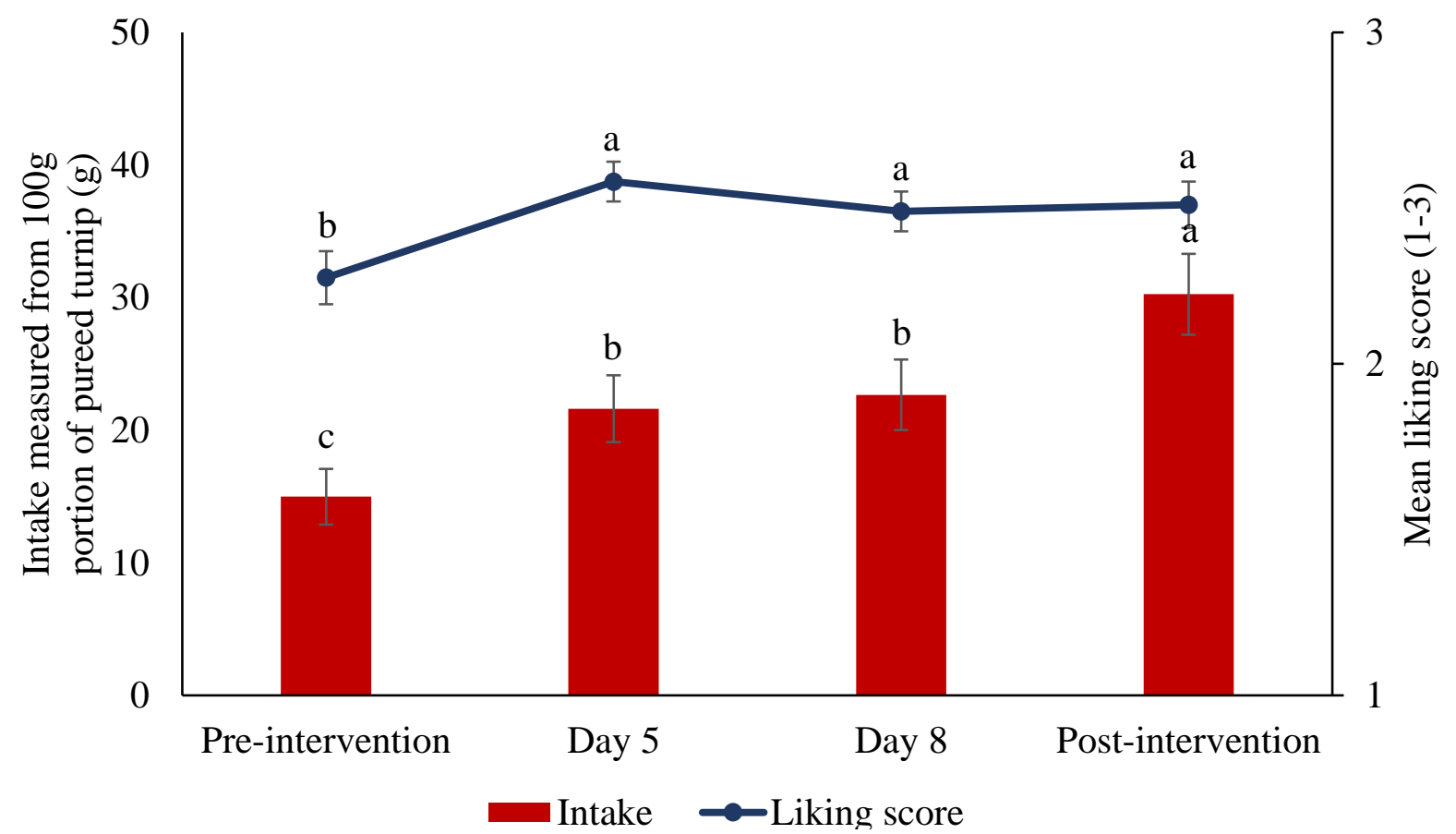

Fig. 5: Change in intake and liking scores for steamed-pureed turnip from pre-intervention, Day 5 and 8 of exposure to post-intervention. Values are means \pm SEM. Differences in letters indicate significant differences between time points. 
Vegetable acceptance during exposure days according to taste genotypes and phenotypes: Taste genotypes and phenotypes were incorporated into the analyses to determine whether these factors interact with time (pre-intervention, Day 5, Day 8 or post-intervention) to determine turnip intake and liking. The significant main effect of time on intake and liking was confirmed in each analysis; however there were no significant main effects of any taste genotype nor phenotype and no interactions between these factors and time (data not shown).

Effects of repeated taste exposure at follow-up: Of 134 children, 121 children participated in the 3 month follow-up. 3-point one-way repeated-measures ANOVA tests were carried out to determine any lasting effect of repeated taste exposure. Results revealed a significant effect of time on intake $\left(\mathrm{F}(1.7,206.1)=42.13, \mathrm{p}<0.001, \eta_{p}^{2}=0.26\right)$. Intake increased significantly from both pre-intervention $(15.5 \pm 25.1 \mathrm{~g}, \mathrm{p}<0.001)$ and post-intervention $(31.4 \pm 35.9 \mathrm{~g}, \mathrm{p}=0.002)$ to follow-up (38.3 $\pm 37.7 \mathrm{~g})$ (Fig. 6).

For liking, there was a significant main effect of time $\left(\mathrm{F}(1.9,222.8)=7.54, \mathrm{p}=0.001, \eta_{p}^{2}=0.06\right)$. Liking increased significantly from pre-intervention $(2.2 \pm 0.9)$ to follow-up $(2.5 \pm 0.8$, $\mathrm{p}=0.001$ ); however, there was no difference in liking from post-intervention to follow-up $(\mathrm{p}=1.00)$.

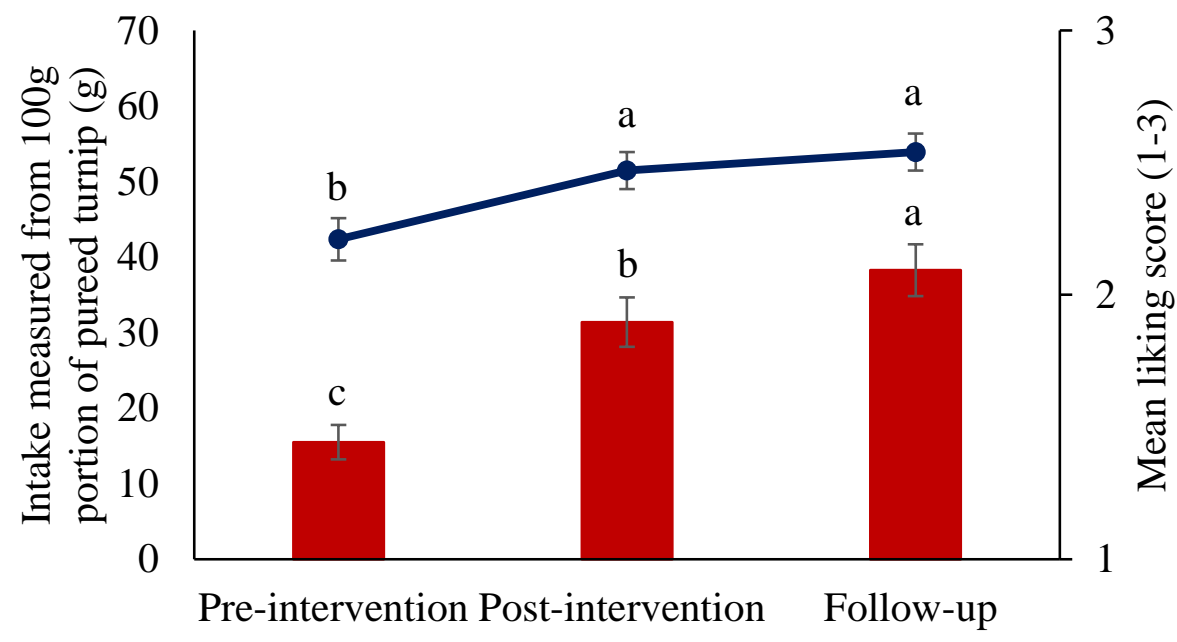

Intake $(\mathrm{g}) \multimap$ Liking

Fig. 6: Intake and liking scores for steamed-pureed turnip at pre-, post-intervention and followup. Values are means \pm SEM. Differences in letters at the top of each bar indicate significant differences $(\mathrm{p}<0.05)$. phenotypes: Taste genotypes and phenotypes were incorporated into the analyses to determine whether these factors interact with time (pre-intervention, post intervention or follow-up) on turnip intake and liking. The significant main effect of time on intake and liking was confirmed in each analysis; however there were no significant main effects of any taste genotype nor 


\section{Discussion}

The findings of this study show that there was a significant increase in overall intake and liking of steamed-pureed turnip over repeated taste exposure. Other studies have found the same effects of repeated taste exposure; for example Ahern, Caton, Blundell and Hetherington (2014) reported that intake of novel vegetables (swede, turnip and celeriac) increased after repeated exposure in preschool children (15 to 56 months). Hausner, Olsen, et al. (2012) described that repeated taste exposure is a powerful strategy to enhance vegetable acceptance as it was found that intake of a novel vegetable (artichoke) increased after 10 exposures in 2to 3-year-old children. Similarly, repeated taste exposure increased the acceptance of initially disliked vegetables (red bell pepper and yellow squash) in 3- to 6-year-old children (AnzmanFrasca et al., 2012). These findings also show that children can learn to like bitter tastes over time if they are given opportunity to taste them repeatedly, even though children are born with a tendency to dislike bitter tastes. However, as our study did not include a non-bitter vegetable as a comparator food, we cannot confirm how the increase in liking of turnip compares to the changes previously reported for less bitter vegetables. In future research it would be interesting to compare the effects of repeated taste exposure between different types of vegetables.

In this study, it was observed that overall intake and liking significantly increased after 5 exposures and that intake continued to increase significantly post-intervention, while liking remained stable. In agreement with previous studies, results indicate that 5 exposures might be sufficient to increase acceptance of a novel vegetable (Caton et al., 2013; Hausner, Olsen, et al., 2012). It was also found that intake and liking increased significantly from pre-intervention to follow-up, which indicates a long-term effect of repeated taste exposure. This result is supported by Caton et al. (2013) and Hausner, Olsen, et al. (2012) who report that repeated taste exposure could increase vegetable acceptance up to 5 weeks and 6 months, respectively.

When intake was evaluated separately according to taste genotypes (TAS2R38 and CA6) and phenotypes (PROP taster status and FPD), no significant effects were found for any taste genotype/phenotype. It is possible that the effects of exposure obscured genuine effects of taste genotypes and phenotypes. This current study is underpowered to conclude a null effect of taste sensitivity on repeated taste exposure as the original sample size calculation was based on effect sizes in studies where no information on taste sensitivity was available. Based on the data from our study, a sample size calculation with $90 \%$ power indicates that 770 children are needed in a future study to conclude whether taste genotypes and phenotypes could significantly affect intake of this bitter vegetable after exposure.

To our knowledge, this is the first study that examines the role of both taste genotype and phenotype on the effects of repeated taste exposure. A previous study by Fisher et al. (2012) investigated both bitter phenotype and repeated taste exposure on liking of broccoli by Hispanic children in the US. In agreement with our study they reported that liking of broccoli increased after 7 weeks of exposure among children, with no difference in rated liking due to PROP sensitivity. The Fisher study used a more thorough PROP phenotype procedure than used in our own study, each child evaluating three concentrations of PROP. They concluded that $30 \%$ of the children were bitter insensitive whereas we found $20 \%$ did not taste the PROP taste papers in our own study. However, the $30 \%$ PROP insensitive number from the more accurate method does fit very well with the $30 \%$ of children with the bitter insensitive AVI/AVI genotype found in our own study. Moving forward we consider that there are a number of advantages to taking the genotype rather than the phenotype measurement approach. We were able to readily determine which children had the "super-sensitive" PAV/PAV genotype $(16 \%)$ 
and which had the "average sensitivity" PAV/AVI genotype (50\%). In addition, bitter sensitive children do not like the taste of PROP, whereas the buccal swab taken for genotyping is quick to administer and has no unpleasant taste or side-effect. In contrast to our own results, the Fisher study reported a decrease of broccoli intake following exposure which the authors suggested could be caused by a monotony effect. Several studies have investigated the effects of taste genotype and phenotype on vegetable intake; for example Bell and Tepper (2006) found that PROP non-taster children consumed more vegetables than tasters. This is also supported by Dinehart, Hayes, Bartoshuk, Lanier and Duffy (2006) who reported that PROP sensitive individuals consumed fewer vegetables, while the same research group found that adults with AVI/AVI TAS2R38 genotype consumed more vegetables (Duffy et al., 2010). Sandell et al. (2014) also found that the less bitter sensitive adults consumed more vegetables than adults with heightened bitter sensitivity.

Although liking increased across the whole sample post-intervention, there were no significant differences according to taste genotype or phenotype group. It is possible that the 3-point hedonic scale that was used in this study was insufficiently sensitive to detect differences in children's liking and that a scale with more than 3-points would have been better. However, it was selected because young children (below 6 years) might have difficulty interpreting wider hedonic scales (e.g. 5- or 7-point scales) (Stone \& Sidel, 2004). Chen, Resurreccion and Paguio (1996) have demonstrated that a 9-point hedonic scale is not suitable for 3- to 5-year-old children, and that 3-, 5- and 7-point scales work best with 3-, 4- and 5-year-old children, respectively. Despite the steps undertaken to ensure children understood how to complete the scale, on a few occasions children rated high liking despite displaying a facial dislike expression on tasting the steamed-pureed turnip. When this happened, researchers re-explained the scale. Future researchers may consider taking additional steps to ensure the reliability of hedonic scales with this age group, for example training children on how to use the scale in advance until their scores are reliable.

Considering the relationship between taste genotypes and phenotypes, our results did not find associations between TAS2R38, FPD, CA6 and PROP taster status. It was expected that children with high FPD, PAV/PAV TAS2R 38 and A/A CA6 would be PROP tasters, and those with low FPD, AVI/AVI TAS2R38 and G/G CA6 would be non-tasters, but there were anomalies. It was found that the number of children categorised as PROP tasters/non-tasters was not always consistent with the expected PAV/PAV or AVI/AVI TAS2R38 genotype. These unexpected results are thought to be due to the simplified method used to identify PROP taster status in this study. Children were categorised into either PROP tasters or non-tasters by tasting just one concentrated level of PROP impregnated into a filter paper, whilst other studies have used a more complex method to separate adult participants into 3 categories (PROP super-, medium- or non-tasters). This method requires participants to taste different concentrations of PROP solutions and sodium chloride $(\mathrm{NaCl})$ solutions and then rate the intensity of the solutions using a labelled magnitude scale (LMS) (Tepper, Christensen, \& Cao, 2001; Shen, Kennedy, \& Methven, 2016). However, Keller and Adise (2016) argued that young children (under 7 years old) would struggle to use more complex scales, and most studies involving children have used a simple forced-choice screening method to categorise them into either tasters or non-tasters, the method selected for the current study. Turnbull and Matisoo-Smith (2002) determined PROP taster status in 3- to 6-year-old children using a more sensitive procedure, in which PROP thresholds and suprathresholds of the children were measured on simple categorical scales. Despite its sensitivity, the method is not practical for a large fieldbased study such as ours as it involves tasting multiple solutions. The relationship between taste genotype and phenotype is complex; as Hayes, Bartoshuk, Kidd and Duffy (2008) 
explained, PROP sensitivity is not entirely dependent on taste genotypes and phenotypes and there might be more than just one receptor (ie: TAS2R38) or mechanism that explains PROP bitter taste sensitivity. Furthermore, Piochi, Dinnella, Prescott, \& Monteleone (2018) concluded that the association between PROP bitter taste sensitivity and FPD is not straightforward as there may be other factors contributing to differences in findings such as age, gender and method variability. In addition, most studies did not consider the quantification of taste buds to provide information about fungiform papillae functionality. It is possible that it is the interactions between genotype and phenotype that have an impact on vegetable intake and liking, rather than taste genotype or phenotype alone; however the number of participants was insufficient to sub-divide groups further in order to investigate these interactions in this study.

\section{Conclusion}

This study confirms that repeated taste exposure is a good method to enhance acceptance of an unfamiliar vegetable in children regardless of their bitter taste sensitivity. Repeated taste exposure is simple and easy for parents to implement in a home-setting environment to encourage children to eat bitter-tasting vegetables. This study also demonstrates that repeated taste exposure is not only effective in the short-term, but remains effective 3 months after exposure.

\section{Acknowledgement}

This research was funded by The Ministry of Higher Education Malaysia. There are no conflicts of interest to report.

\section{References}

Ahern, S. M., Caton, S. J., Blundell, P., \& Hetherington, M. M. (2014). The root of the problem: increasing root vegetable intake in preschool children by repeated exposure and flavour flavour learning. Appetite, 80, 154-160. http://doi.org/10.1016/j.appet.2014.04.016

Anzman-Frasca, S., Savage, J. S., Marini, M. E., Fisher, J. O., \& Birch, L. L. (2012). Repeated exposure and associative conditioning promote preschool children's liking of vegetables. Appetite, 58, 543-553. http://doi.org/10.1016/j.appet.2011.11.012

Appleton, K. M., Hemingway, A., Rajska, J., \& Hartwell, H. (2018). Repeated exposure and conditioning strategies for increasing vegetable liking and intake: systematic review and meta-analyses of the published literature. American Journal of Clinical Nutrition, 108, 842-856. http://doi.org/10.1093/ajcn/nqy143

Barajas-Ramírez, J. A., Quintana-Castro, R., Oliart-Ros, R. M., \& Angulo-Guerrero, O. (2016). Bitter taste perception and TAS2R38 genotype: effects on taste sensitivity, food consumption and anthropometry in Mexican adults. Flavour and Fragrance Journal, 31, 310-318. http://doi.org/10.1002/ffj.3319

Bates, B., Cox, L., Page, S. N. P., Prentice, A., Steer, T., \& Swan, G. (2016). National Diet and Nutrition Survey: Results from Years 5 and 6 (combined) of the Rolling Programme (2012/2013-2013/2014). Public Health England, London, UK. London, UK.

Bates, B., Lennox, A., Prentice, A., Bates, C., Page, P., Nicholson, S., \& Swan, G. (2014). National Diet and Nutrition Survey Results from Years 1, 2, 3 and 4 (combined) of the Rolling Programme (2008/2009-2011/2012). London, UK.

Bell, K. I., \& Tepper, B. J. (2006). Short-term vegetable intake by young children classified 
by 6-n-propylthoiuracil bitter-taste phenotype. American Journal of Clinical Nutrition, $84,245-251$.

Birch, L. L. (1999). Development of food preferences. Annual Review of Nutrition, 19, 4162.

Bouthoorn, S. H., van Lenthe, F. J., Kiefte-de Jong, J. C., Taal, H. R., Wijtzes, A. I., Hofman, A., Jaddoe, V. W. V., Glymour, M. M., Rivadeneira, F., \& Raat, H. (2014). Genetic taste blindness to bitter and body composition in childhood: A Mendelian randomization design. International Journal of Obesity, 38, 1005-1010. http://doi.org/10.1038/ijo.2013.141

Bufe, B., Breslin, P. A. S., Kuhn, C., Reed, D. R., Tharp, C. D., Slack, J. P., Kim, U.-K., Drayna, D., \& Meyerhof, W. (2005). The molecular basis of individual differences in phenylthiocarbamide and propylthiouracil bitterness perception. Current Biology, 15, 322-327.

Caton, S. J., Ahern, S. M., Remy, E., Nicklaus, S., Blundell, P., \& Hetherington, M. M. (2013). Repetition counts: repeated exposure increases intake of a novel vegetable in UK pre-school children compared to flavour-flavour and flavour-nutrient learning. British Journal of Nutrition, 109, 2089-2097. http://doi.org/10.1017/S0007114512004126

Chen, A. W., Resurreccion, A. V. A., \& Paguio, L. P. (1996). Age appropriate hedonic scales to measure food preferences of young children. Journal of Sensory Studies, 11, 141-163. http://doi.org/10.1111/j.1745-459X.1996.tb00038.x

Cooke, L., Wardle, J., \& Gibson, E. L. (2003). Relationship between parental report of food neophobia and everyday food consumption in 2-6-year-old children. Appetite, 41, 205206. http://doi.org/10.1016/S0195-6663(03)00048-5

Dias, J. S. (2012). Nutritional quality and health benefits of vegetables: A review. Food and Nutrition Sciences, 3, 1354-1374. http://doi.org/10.4236/fns.2012.310179

Dinehart, M. E., Hayes, J. E., Bartoshuk, L. M., Lanier, S. L., \& Duffy, V. B. (2006). Bitter taste markers explain variability in vegetable sweetness, bitterness, and intake. Physiology and Behavior, 87, 304-313. http://doi.org/10.1016/j.physbeh.2005.10.018

Dinnella, C., Monteleone, E., Piochi, M., Spinelli, S., Prescott, J., Pierguidi, L., Gasperi, F., Laureati, M., Pagliarini, E., Predieri, S., Torri, L., Barbieri, S., Valli, E., Bianchi, P., Braghieri, A., Caro, A. D., Di Monaco, R., Favotto, S., \& Moneta, E. (2018). Individual variation in PROP status, fungiform papillae density, and responsiveness to taste stimuli in a large population sample. Chemical Senses, 43, 697-710. http://doi.org/10.1093/chemse/bjy058

Duffy, V. B., Davidson, A. C., Kidd, J. R., Kidd, K. K., Speed, W. C., Pakstis, A. J., Reed, D. R., Snyder, D. J., \& Bartoshuk, L. M. (2004). Bitter receptor gene (TAS2R38), 6-npropylthiouracil (PROP) bitterness and alcohol intake. Alcoholism, Clinical and Experimental Research, 28(11), 1629-1637. http://doi.org/Doi 10.1097/01.Alc.0000145789.55183.D4

Duffy, V. B., Hayes, J. E., Davidson, A. C., Kidd, J. R., Kidd, K. K., \& Bartoshuk, L. M. (2010). Vegetable intake in college-aged adults is explained by oral sensory phenotypes and TAS2R38 genotype. Chemosensory Perception, 3(3-4), 137-148. http://doi.org/10.1007/s12078-010-9079-8

Feeney, E. L., \& Hayes, J. E. (2014). Regional differences in suprathreshold intensity for bitter and umami stimuli. Chemosensory Perception, 7(3-4), 147-157. http://doi.org/10.1007/s12078-014-9166-3

Feeney, E. L., O’Brien, S. A., Scannell, A. G. M., Markey, A., \& Gibney, E. R. (2014). Genetic and environmental influences on liking and reported intakes of vegetables in Irish children. Food Quality and Preference, 32, 253-263. 
http://doi.org/10.1016/j.foodqual.2013.09.009

Fischer, M. E., Cruickshanks, K. J., Schubert, C. R., Pinto, A., Klein, R., Pankratz, N., Pankow, J. S., \& Huang, G.-H. (2013). Factors related to fungiform papillae density: The Beaver Dam Offspring Study. Chemical Senses, 38, 669-677. http://doi.org/10.1093/chemse/bjt033

Fisher, J. O., Mennella, J. A., Hughes, S. O., Liu, Y., Mendoza, P. M., \& Patrick, H. (2012). Offering "dip" promotes intake of a moderately-liked raw vegetable among preschoolers with genetic sensitivity to bitterness. Journal of the Academy of Nutrition and Dietetics, 112, 235-245. http://doi.org/10.1016/j.jada.2011.08.032

Galindo, M. M., Schneider, N. Y., Stähler, F., Töle, J., \& Meyerhof, W. (2012). Taste preferences. Progress in Molecular Biology and Translational Science, 108, 383-426. http://doi.org/10.1016/B978-0-12-398397-8.00015-0

Garneau, N. L., Nuessle, T. M., Sloan, M. M., Santorico, S. A., Coughlin, B. C., \& Hayes, J. E. (2014). Crowdsourcing taste research: Genetic and phenotypic predictors of bitter taste perception as a model. Frontiers in Integrative Neuroscience, 8, 33. http://doi.org/10.3389/fnint.2014.00033

Hausner, H., Olsen, A., \& Møller, P. (2012). Mere exposure and flavour-flavour learning increase 2-3year-old children's acceptance of a novel vegetable. Appetite, 58, 11521159. http://doi.org/10.1016/j.appet.2012.03.009

Hayes, J. E., Bartoshuk, L. M., Kidd, J. R., \& Duffy, V. B. (2008). Supertasting and PROP bitterness depends on more than the TAS2R38 gene. Chemical Senses, 33, 255-265. http://doi.org/10.1093/chemse/bjm084

Hayes, J. E., Sullivan, B. S., \& Duffy, V. B. (2010). Explaining variability in sodium intake through oral sensory phenotype, salt sensation and liking. Physiology \& Behavior, 100(4), 369-380. http://doi.org/10.1016/j.biotechadv.2011.08.021.

Heath, P. (2012). Improving children's responses to fruit and vegetables: Picture-book exposure and the impact of food familiarity and liking. University of Reading.

Henkin, R. I., Martin, B. M., \& Agarwal, R. P. (1999). Decreased parotid saliva gustin/carbonic anhydrase VI secretion: An enzyme disorder manifested by gustatory and olfactory dysfunction. The American Journal of the Medical Sciences, 318(6), 380391. http://doi.org/10.1016/S0002-9629(15)40663-9

Keller, K. L., \& Adise, S. (2016). Variation in the Ability to Taste Bitter Thiourea Compounds: Implications for Food Acceptance, Dietary Intake, and Obesity Risk in Children. Annual Review of Nutrition, 36, 157-182. http://doi.org/10.1146/annurev-nutr071715-050916

Keller, K. L., Steinmann, L., Nurse, R. J., \& Tepper, B. J. (2002). Genetic taste sensitivity to 6-n-propylthiouracil influences food preference and reported intake in preschool children. Appetite, 38, 3-12. http://doi.org/10.1006/appe.2001.0441

Kim, U., Jorgenson, E., Coon, H., Leppert, M., Risch, N., \& Drayna, D. (2003). Positional cloning of the human quantitative trait locus underlying taste sensitivity to phenylthiocarbamide. Science, 299, 1221-1225.

Kim, U., Wooding, S., Ricci, D., Jorde, L. B., \& Drayna, D. (2005). Worldwide haplotype diversity and coding sequence variation at human bitter taste receptor loci. Human Mutation, 26(3), 199-204. http://doi.org/10.1002/humu.20203

Lakkakula, A., Geaghan, J., Zanovec, M., Pierce, S., \& Tuuri, G. (2010). Repeated taste exposure increases liking for vegetables by low-income elementary school children. Appetite, 55, 226-231. http://doi.org/10.1016/j.appet.2010.06.003

Lumeng, J. C., Cardinal, T. M., Sitto, J. R., \& Kannan, S. (2008). Ability to taste 6-npropylthiouracil and BMI in low-income preschool-aged children. Obesity, 16, 15221528. http://doi.org/10.1038/oby.2008.227 
Micha, R., Khatibzadeh, S., Shi, P., Andrews, K. G., Engell, R. E., \& Mozaffarian, D. (2015). Global, regional and national consumption of major food groups in 1990 and 2010: A systematic analysis including 266 country-specific nutrition surveys worldwide. $B M J$ Open, 5(e008705). http://doi.org/10.1136/bmjopen-2015-008705

Mikkilä, V., Räsänen, L., Raitakari, O. T., Pietinen, P., \& Viikari, J. (2004). Longitudinal changes in diet from childhood into adulthood with respect to risk of cardiovascular diseases: The Cardiovascular Risk in Young Finns Study. European Journal of Clinical Nutrition, 58, 1038-1045. http://doi.org/10.1038/sj.ejcn.1601929

Office for National Statistics. (2015). Harmonised concepts and questions for social data sources. Retrieved May 1, 2015, from https://www.ons.gov.uk/ons/guidemethod/harmonisation/primary-set-of-harmonised-concepts-and-questions/ethnicgroup.pdf

Padiglia, A., Zonza, A., Atzori, E., Chillotti, C., Calò, C., Tepper, B. J., \& Barbarossa, I. T. (2010). Sensitivity to 6-n-propylthiouracil is associated with gustin (carbonic anhydrase VI) gene polymorphism, salivary zinc, and body mass index in humans. American Journal of Clinical Nutrition, 92, 539-545. http://doi.org/10.3945/ajen.2010.29418

Pelchat, M. L., \& Pliner, P. (1995). “ Try it . You'll like it.” Effects of information on willingness to try novel foods. Appetite, 24, 153-166. http://doi.org/10.1016/S01956663(95)99373-8

Piochi, M., Dinnella, C., Prescott, J., \& Monteleone, E. (2018). Associations between human fungiform papillae and responsiveness to oral stimuli: effects of individual variability, population characteristics, and methods for papillae quantification. Chemical Senses, 43, 313-327. http://doi.org/10.1093/chemse/bjy015

Piochi, M., Pierguidi, L., Torri, L., Spinelli, S., Monteleone, E., Aprea, E., Arena, E., Borgogno, M., Cravero, M. C., Galassi, L., Gatti, E., Lozano, L., Musi, V., Piasentier, E., Valli, E., \& Dinnella, C. (2019). Individual variation in fungiform papillae density with different sizes and relevant associations with responsiveness to oral stimuli. Food Quality and Preference, 78, 103729. http://doi.org/10.1016/j.foodqual.2019.103729

Remy, E., Issanchou, S., Chabanet, C., \& Nicklaus, S. (2013). Repeated exposure of infants at complementary feeding to a vegetable purée increases acceptance as effectively as flavor-flavor learning and more effectively than flavor-nutrient learning. The Journal of Nutrition, 143, 1194-1200. http://doi.org/10.3945/jn.113.175646

Russell, C. G., \& Worsley, A. (2008). A population-based study of preschoolers' food neophobia and its associations with food preferences. Journal of Nutrition Education and Behavior, 40, 11-19. http://doi.org/10.1016/j.jneb.2007.03.007

Sacerdote, C., Guarrera, S., Smith, G. D., Grioni, S., Krogh, V., Masala, G., Mattiello, A., Palli, D., Panico, S., Tumino, R., Veglia, F., Matullo, G., \& Vineis, P. (2007). Lactase persistence and bitter taste response: Instrumental variables and Mendelian randomization in epidemiologic studies of dietary factors and cancer risk. American Journal of Epidemiology, 166(5), 576-581. http://doi.org/10.1093/aje/kwm113

Sandell, M. A., \& Breslin, P. A. S. (2006). Variability in a taste-receptor gene determines whether we taste toxins in food. Current Biology, 16(18), R792-R794. http://doi.org/10.1016/j.cub.2006.08.049

Sandell, M., Hoppu, U., Mikkilä, V., Mononen, N., Kähönen, M., Männistö, S., Rönnemaa, T., Viikari, J., Lehtimäki, T., \& Raitakari, O. T. (2014). Genetic variation in the hTAS2R38 taste receptor and food consumption among Finnish adults. Genes and Nutrition, 9(433), 1-8. http://doi.org/10.1007/s12263-014-0433-3

Shahbake, M., Hutchinson, I., Laing, D. G., \& Jinks, A. L. (2005). Rapid quantitative assessment of fungiform papillae density in the human tongue. Brain Research, 1052, 196-201. http://doi.org/10.1016/j.brainres.2005.06.031 
Shen, Y., Kennedy, O. B., \& Methven, L. (2016). Exploring the effects of genotypical and phenotypical variations in bitter taste sensitivity on perception, liking and intake of brassica vegetables in the UK. Food Quality and Preference, 50, 71-81. http://doi.org/10.1016/j.foodqual.2016.01.005

Spill, M. K., Johns, K., Callahan, E. H., Shapiro, M. J., Wong, Y. P., Benjamin-Neelon, S. E., Birch, L., Black, M. M., Cook, J. T., Faith, M. S., Mennella, J. A., \& Casavale, K. O. (2019). Repeated exposure to food and food acceptability in infants and toddlers: a systematic review. American Journal of Clinical Nutrition, 109 (Suppl, 978S-989S. http://doi.org/10.1093/ajcn/nqy308

Stone, H., \& Sidel, J. L. (2004). Sensory evaluation practices (3rd ed.). San Diego, CA: Academic Press.

Tepper, B. J., Christensen, C. M., \& Cao, J. (2001). Development of brief methods to classify individuals by PROP taster status. Physiology and Behavior, 73, 571-577. http://doi.org/10.1016/S0031-9384(01)00500-5

Turnbull, B., \& Matisoo-Smith, E. (2002). Taste sensitivity to 6- n -propylthiouracil predicts acceptance of bitter-tasting spinach in 3-6-7-old children. The American Journal of Clinical Nutrition, 76, 1101-1105.

Van Duyn, M. A. S., \& Pivonka, E. (2000). Overview of the health benefits of fruit and vegetable consumption for the dietetics professional: Selected literature. Journal of the American Dietetic Association. http://doi.org/10.1016/S0002-8223(00)00420-X

Wardle, J., Cooke, L. J., Gibson, E. L., Sapochnik, M., Sheiham, A., \& Lawson, M. (2003a). Increasing children's acceptance of vegetables; a randomized trial of parent-led exposure. Appetite, 40(2), 155-162. http://doi.org/10.1016/S0195-6663(02)00135-6

Wardle, J., Herrera, M.-L., Cooke, L., \& Gibson, E. L. (2003b). Modifying children's food preferences: the effects of exposure and reward on acceptance of an unfamiliar vegetable. European Journal of Clinical Nutrition, 57(2), 341-348.

Wardle, J., Sanderson, S., Gibson, E. L., \& Rapoport, L. (2001). Factor-analytic structure of food preferences in four-year-old children in the UK. Appetite, 37, 217-223. http://doi.org/10.1006/appe.2001.0423

Yackinous, C. A., \& Guinard, J.-X. (2002). Relation between PROP (6-n-propylthiouracil) taster status, taste anatomy and dietary intake measures for young men and women. Appetite, 38, 201-209. http://doi.org/10.1006/appe.2001.0481

Zhao, L., Kirkmeyer, S. V., \& Tepper, B. J. (2003). A paper screening test to assess genetic taste sensitivity to 6-n-propylthiouracil. Physiology and Behavior, 78, 625-633. http://doi.org/10.1016/S0031-9384(03)00057-X 